\title{
Effect of Air Pollution on Salivary Interleukin-8 Levels in Children
}

${ }^{1}$ Solmaz Pourzare Mehrbani, ${ }^{2}$ Zohreh Babaloo, ${ }^{3}$ Zahra Jamali, ${ }^{4}$ Tahmoores Abdollahian, ${ }^{5}$ Hosein Eslami, ${ }^{6}$ Narges Sobhani

\section{ABSTRACT}

Background: Air pollution in cities has always been a permanent and serious threat for the health of society and the environment, influencing the health of different body organs and systems both acutely and chronically. Therefore, the aim of this study is to investigate the effect of air pollution in saliva Interleukin-8 (IL-8) levels in children.

Materials and methods: A total of 88,8 - to 10 -year-old children were included in this descriptive cross-sectional study. Group I, the case group, included 44 children from Tabriz (Iranian Azerbaijan), and group II, the control group, included 44 children from Kalibar Town (of Tabriz). Both groups in this study had a similar economic status. Following sampling and selection of individuals, for measuring the levels of saliva IL-8, ELISA (enzyme-linked immunosorbent assay) method was used. To investigate the difference between the means of the groups, independent t test or its nonparametric equivalent, i.e., Man-Whitney test and Statistical Package for the Social Sciences (SPSS) 21 were used. In this study, p-value lower than 0.05 was considered statistically significant.

Results: The results of this study indicate a significant difference in the levels of saliva IL- 8 between the two groups, where the mean level of saliva IL- 8 is greater in children residing in the region with higher air pollution level than in the children dwelling in the region with a greater air pollution level $(p=0.001)$.

Conclusion: The results obtained from this study indicated that the level of saliva IL-8 increases in regions with air pollution, potentially causing several mouth problems in children.

Keywords: Air pollution, Interleukin-8, Salivary.

How to cite this article: Mehrbani SP, Babaloo Z, Jamali Z, Abdollahian T, Eslami $H$, Sobhani N. Effect of Air Pollution on Salivary Interleukin-8 Levels in Children. World J Dent 2016;7(4):175-178.

Source of support: Nil

Conflict of interest: None

\footnotetext{
1,4,5 Assistant Professor, ${ }^{2,3}$ Associate Professor, ${ }^{6}$ Dentist

1,3-5 Department of Oral and Maxillofacial Medicine, Dental and Periodontal Research Center, Tabriz University of Medical Sciences, Tabriz, Islamic Republic of Iran

${ }^{2}$ Department of Immunology, Tabriz University of Medical Sciences, Tabriz, Islamic Republic of Iran

${ }^{6}$ Private Practice, Tabriz, Islamic Republic of Iran

Corresponding Author: Hosein Eslami, Assistant Professor Department of Oral and Maxillofacial Medicine, Dental and Periodontal Research Center, Tabriz University of Medical Sciences Tabriz, Islamic Republic of Iran, Phone: +00989143922448, e-mail: eslamihosein56@yahoo.com
}

\section{INTRODUCTION}

Air pollution in cities is always a permanent and serious threat to the health of the society and environment, ${ }^{1}$ affecting the health of organs and body systems both acutely and chronically. These effects include high or trivial respiratory irritations, chronic cardiac or pulmonary diseases, lung cancer, acute respiratory infections in children and chronic bronchitis in adults, deterioration of pulmonary and cardiac diseases, and asthma attacks. ${ }^{2}$ The effects of air pollution on human health has always been of great concern. The mechanisms of the effects of air pollution on human being are complex and poorly understood. ${ }^{3}$

According to a report by World Health Organization in 2014, around 7 million people lost their lives in 2012 due to air pollution, being twice the value of predictions. The statistics also show that over 3 million and 700,000 people have lost their lives due to air pollution in the outer space in cities and villages around the world. ${ }^{4}$

As the level of air pollution is increasing in some cities, respiratory diseases have changed into one of the major concerns for people. ${ }^{5}$ There is also a significant relationship between the level of suspended solids with a diameter less than 10 micron and contraction of heart diseases. ${ }^{6}$ There are different organic and inorganic compounds in saliva, whose secretion changes in response to environmental variations. Wilhelm et $\mathrm{al}^{7}$ revealed that the amount of lead found in the saliva of individuals living in high-traffic regions is greater. Cytokines, an organic compound, have attracted a great deal of attention due to their significant role in the pathogenesis and treatment of cancer and inflammatory, autoimmune diseases. ${ }^{8}$ Interleukin-8 (IL-8) is a chemokine produced by macrophages and other cells, including epithelial cells, the smooth muscle cells of the airway, and endothelial cells. ${ }^{9}$

There are many receptors on the surface membrane of cells capable of attaching to IL-8. Interleukin- 8 is an important intermediate in host response to tissue damages and inflammation, and as activator of neutrophils, neutrophilic and basophilic chemotactic. Activation of neutrophils by IL-8 results in development of enzymes involved in tissue degeneration and development of lesions. ${ }^{10}$

\section{MATERIALS AND METHODS}

This analytical cross-sectional study was conducted on 88 8- to 10-year-old girls residing in Tabriz and Kalibar 
Table 1: Statistical description of IL-8 levels in terms of the studied groups

\begin{tabular}{llllll}
\hline $\begin{array}{l}\text { Normality test Kolmogorov } \\
\text { index Z }\end{array}$ & $p$-value & Maximum & Minimum & $\begin{array}{l}\text { Mean } \pm \text { standard } \\
\text { deviation } n=44\end{array}$ & $\begin{array}{l}\text { Statistical information } \\
\text { of groups }\end{array}$ \\
\hline 1.551 & 0.001 & 290.7 & 25.5 & $108.43 \pm 11.04$ & Kalibar \\
0.757 & 0.001 & 867.9 & 80.03 & $291.88 \pm 26.51$ & Tabriz \\
\hline
\end{tabular}

(subsidiary of Tabriz) with a similar socioeconomic status, but with different air pollutions. As many as 44 children dwelling in Tabriz and 44 other children residing in Kalibar were placed in groups I and II respectively. The level of urban pollutants including ozone $\left(\mathrm{O}_{3}\right)$, nitrogen dioxide $\left(\mathrm{NO}_{2}\right)$, carbon monoxide $(\mathrm{CO})$, and sulfur dioxide $\left(\mathrm{SO}_{2}\right)$ was measured for 4 months (February 2014 to May 2014) in two regions chosen by the environmental experts in eastern Azerbaijan. The pollutant standard index (PSI) is a standard used for daily reporting of air quality, commonly consisting of the five pollutants of $\mathrm{CO}, \mathrm{O}_{3}, \mathrm{NO}_{2}, \mathrm{SO}_{2}$, and particulate matters. Considering the concentration of pollutants and the health standards of environmental protection agency of the United States, the concentration of pollutants is converted to a numerical scale between 0 and 500 PSI. Pollutant standard index is of priority since it measures the concentration of pollutants based on a single scale. ${ }^{11}$ The level of these pollutants in the air of Tabriz was far greater than in Kalibar Town. Note that the level of pollutants in the air of Kalibar was so low that the air pollution measurement device was not able to detect it, whereas these values were far higher in Tabriz. The sampling was conducted through multistages, where some schools were selected randomly and then through clustering in each region. Next, in each school, proportion with the number of students, and taking the sample volume into consideration, the samples of interest were chosen. The samples should reside in the same region and be present in that region at least for 1 year. They should also use urban gas in their house for heating and cooking purposes. The children who were either actively or passively under exposure to smoke or had intraoral active infections including periodontal disease, abscess, or systemic diseases, including immunosuppressive and autoimmune diseases along with diabetes, were not taken samples of saliva. In this study, spitting method was used for saliva collection. ${ }^{12}$ The time of saliva collection was 9 to $10 \mathrm{am}$. The instructions that no food to be consumed 90 minutes prior to the experiment was given to the participants. ${ }^{13}$ Following saliva collection, the samples were transferred to laboratory where, through enzyme-linked immunosorbent assay (ELISA) method and a special kit, the level of IL- 8 was measured and recorded in the volume unit of each sample. The data of each group were calculated descriptively, and for investigating the difference in the mean between the two groups, independent $t$ test or its nonparametric equivalents, i.e., Man-Whitney test along

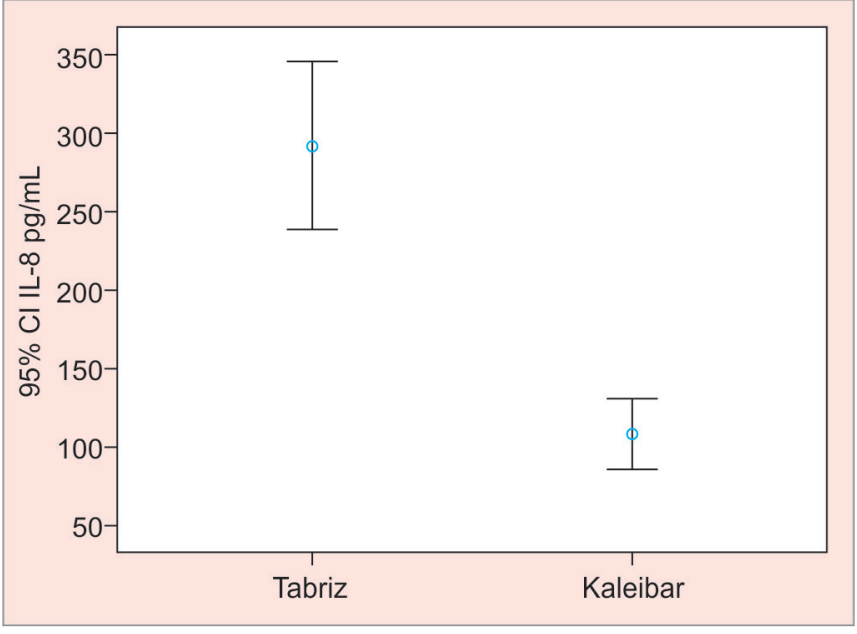

Graph 1: The Error-bar diagram of the level of IL-8 according to the grouping

with Statistical Package for the Social Sciences (SPSS) 19, were employed. In this study, a p-value less than 0.05 was considered statistically significant.

\section{RESULTS}

The results obtained from this study were analyzed for levels of IL-8 in children residing in Tabriz and Kalibar, using independent $t$ test for each group, with the results shown in Table 1. Therefore, the mean level of IL-8 in the saliva of children into two regions of Tabriz and Kalibar has a significantly different degree of pollution. As was shown, the values were obtained to be almost three times different $(\mathrm{df}=57.5, \mathrm{p}=0.001)$. The results showed that the $\mathrm{SD} \pm$ mean of the saliva's IL-8 level in children of Tabriz and of Kalibar was $291.8 \pm 26.5$ and $108.4 \pm 11.04$ picogram $/ \mathrm{mL}$ of saliva respectively, according to the error type one of $\alpha=0.05$ and confidence range of $95 \%$. This suggests increased levels of the interleukin biomarker as much as three times in children residing in Tabriz when compared with children dwelling in Kalibar (Table 1, Graph 1).

\section{DISCUSSION}

The results of this study, similar to a previous research, support the significant increase in the levels of saliva IL-8 in children residing in more polluted regions. Since saliva IL-8 is a cytokine that play an important role in pathogenesis and treatment of cancer and inflammatory and autoimmune diseases, ${ }^{8}$ based on the positive relationship between IL-8 and neutrophils in patients suffering from pulmonary diseases, ${ }^{12,13}$ the aim of this study was 
to investigate the level of saliva IL- 8 in two different regions. The increase in the level of this saliva cytokine due to air pollution can cause increased inflammation and development of mucosal lesions.

Air pollution particulates caused cytokine-induced neutrophil chemoattractant-dependent inflammation of rat lungs. This particulates stimulated interleukin-6 (IL-6) and IL- 8 production, increased IL- 8 messenger RNA (mRNA) and enhanced expression of intercellular adhesion molecule-1 (ICAM-1) in cultured BEAS-2B cells, and stimulated IL-8 secretion in primary cultures of human bronchial epithelium. Cytokine secretion was preceded by activation of the transcription factor nuclear factor- $\kappa B$ $(\mathrm{NF}-\kappa \mathrm{B})$ and was reduced by treatment of cultures with superoxide dismutase, deferoxamine, or $N$-acetylcysteine. These biologic effects were replicated by culturing BEAScells with quantities of $\mathrm{Cu}^{2+}$ found in air pollution extract. Interleukin- 8 secretion by BEAS cells could be modified by addition of normal constituents of airway lining fluid to the culture medium. Mucin significantly reduced IL-8 secretion, and ceruloplasmin significantly increased IL-8 secretion and activation of NF- $\kappa \mathrm{B}$. These findings suggest that copper ions may cause some of the biologic effects of inhaled particulate air pollution. ${ }^{14}$

These air contaminants may affect allergen-induced inflammation by initiating $\mathrm{TH} 2$ responses to antigens or by exacerbating such inflammation in persons already sensitized. $^{15}$

In the study by Bernstein et al, ${ }^{6}$ it was found that there is a significant relationship between the levels of particulate matters with a diameter lower than 10 micron and contraction of heart diseases. Wilhelm et al showed that the amount of lead found in the saliva of people residing in polluted and high-traffic regions is greater. ${ }^{16}$ Similarly, in our study, the level of urban pollutants including $\mathrm{O}_{3}$, $\mathrm{NO}_{2}, \mathrm{CO}$, and $\mathrm{SO}_{2}$ was measured, and the level of these pollutants was far greater than the standard level.

In the review by Romieu et $\mathrm{al}^{13}$ it was found that the people exposed to air pollution elements have a higher level of their biomarkers of IL- 6 and IL- 8 . Further, in the research by Steerenberg et al, ${ }^{16}$ it was demonstrated that the level of IL- 8 in nasal secretions of urban children was $32 \%$ greater than in rural children. In the study by Drumm et $\mathrm{al}_{,}^{17}$ it was indicated that expression of the gene of IL-8 in the macrophages of pulmonary alveoli was significantly increased in response to air pollution. In the study by Abdolsamadi et $\mathrm{al}^{18}{ }^{18}$ it was revealed that the concentration of cytokine increased in the serum of patients with aphthous stomatitis. In another study, it was indicated that the serum level of IL- 8 and IL- 6 increased in patients suffering from relapsing aphthous stomatitis, when compared with healthy individuals. ${ }^{19}$ Regarding IL-8, this growth is very considerable. However, there are few studies that show air pollution causes decreased immunity in children. ${ }^{20}$

\section{CONCLUSION}

The results imply that there was a significant and direct relationship between the level of saliva IL-8 and air pollution levels in Tabriz. This finding highlights that the air pollution in industrial cities, such as Tabriz has been involved in stimulation of generation and elevation of IL-8 levels in the saliva of children between 9 and 11 years old, unlike healthy cities with clean air, such as Kalibar. As the immune regulation mechanism of the receptors of IL-8 has a special relationship with the protective and immune system of the body and preservation of the immune homeostasis of oral cavity, it can be used in epidemiology of air pollution especially in the studied children.

\section{ACKNOWLEDGMENTS}

Authors highly appreciate the dental and periodontal research center of Tabriz University of Medical Sciences for providing the cost of implementation of this research plan.

\section{REFERENCES}

1. Jamshidi A, Karimzadeh K, Raigan Shirazi A. Study of particulate air pollution Gachsaran in 2005. J Armaghan Danesh 2007;12(2):89-97.

2. Sharifi A, Broumand N. Study of air pollution effect on human's health in 2012. Available from: http://www.civilica. com/Paper-SDCONF01-SDCONF01_1951.html

3. Kunzli N, Kaiser R, Studnicka M, Chanel O, Filliger P, Herry M, Horak F Jr, Puybonnieux-Texier V, Quénel P, Schneider J, et al. Public health impact of outdoor and trafficrelated air pollution: a European assessment. Lancet 2000 Sep;356(9232):795-801.

4. Mateen FJ, Brook RD. Air pollution as an emerging global risk factor for stroke. JAMA 2011 Mar;305(12):1240-1241.

5. Makra L, Matyasovszky I, Balint B. Association of allergic asthma emergency room visits with the main biological and chemical air pollutants. Sci Total Environ 2012 Aug;432:288-296.

6. Bernstein JA, Neil A, Barnes C, Bernstein IL, Nel A, Peden D, Diaz-Sanchez D, Tarlo SM, Williams PB. Health effects of air pollution. J Allergy Clin Immunol 2004 Nov;114(5):1116-1123.

7. Wilhelm M, Pesch A, Rostek U, Begerow J, Schmitz N, Idel $\mathrm{H}$, et al. Concentrations of lead in blood, hair and saliva of German children living in three different areas of traffic density. Sci Total Environ 2002 Oct;297(1-3):109.

8. Aggarwal B. Human cytokines. 3rd ed. Philadelphia: Saunders Co; 2004: p. 36-41.

9. al-Dalan A, al-Sedairy S, al-Balaa S, al-Janadi M, Elramahi K, Bahari S, Siddiqui S. Enhanced interleukin-8 secretion in circulation of patients with Behcets disease. J Rheumatol 1995;22(5):904-907.

10. Peichl P, Ceska M, Broell H, Effenberger F, Lindley IJ. Human neutrophil activating peptide/interleukin-8 acts as an autoantigen in rheumatoid arthritis. Ann Rhenum Dis 1992 Jan;51(1):19-22. 
11. Computation of the Pollutant Standards Index (PSI) (PDF). National Environment Agency of Singapore. Retrieved 15 April 2014.

12. Epstein SR, Mandel I, Scopp IW. Salivary composition and calculus formation in patients undergoing hemodialysis. J Periodontol 1980 Jun;51(6):336-338.

13. Romieu I, Castro-Giner F, Kunzli N, Sunyer J. Air pollution, oxidative stress and dietary supplementation: a review. Eur Respir J 2008 Jan;31(1):179-197.

14. Kennedy T, Ghio AJ, Reed W, Samet J, Zagorski J, Quay J, Carter J, Dailey L, Hoidal JR, Devlin RB. Copper-dependent inflammation and nuclear factor- $\kappa \mathrm{B}$ activation by particulate air pollution. Am J Respir Cell Mol Biol 1998 Sep;19(3):366-378.

15. Tatum AJ, Shapiro GG. The effects of outdoor air pollution and tobacco smoke on asthma. Immunol Allergy Clin North Am 2005 Feb;25(1):15-30.

16. Steerenberg PA, Nierkens $S$, Fischer PH, van Loveren $H$, Opperhuizen A, Vos JG, van Amsterdam JG. Traffic-related air pollution affects peak expiratory flow, exhaled nitric oxide, and inflammatory nasal markers. Arch Environ Health 2001 Mar-APr;56(2):167-174.

17. Drumm K, Schindler H, Buhl R, Kustner E, Smolarski R, Kienast K. Indoor air pollutants stimulate interleukin8-specific Mrna expression and protein secretion of alveolar macrophages. Lung 1999;177(1):9-19.

18. Abdolsamadi HR, Kasraie S. Comparison of serum interleukin-8 levels in patients with recurrent aphthous stomatitis and healthy individuals. J Islamic Dent Assoc Iran 2007;19(1):78-82.

19. Vahedi M, Abdollahzadeh SH, Abdolsamadi HR, Hajilooi M, Bakianian Vaziri P. Evaluation of serum levels of interleukin-6 and -8 in patients with recurrent aphthous ulcerations. J Dent 2009;9(4):21-26.

20. Liu L, Poon R, Chen L, Frescura A, Montuschi P, Ciabattoni G, Wheeler A, Dales R. Acute effects of air pollution on pulmonary function, airway inflammation, and oxidative stress in asthmatic children. Environ Health Perspectives 2009 Apr;117(4):668-674. 